\title{
DINHEIRO, AFETO, SEXUALIDADE: A RELAÇÃO DE PROSTITUTAS COM SEUS CLIENTES
}

\author{
Fernanda Burbulhan* \\ Roberto Mendes Guimarães ${ }^{\#}$ \\ Maria Alves de Toledo Bruns
}

\begin{abstract}
RESUMO. A prostituição é alvo constante de diferentes olhares, e para desvelar alguns de seus significados, resolvemos estudar a relação estabelecida entre a prostituta e o seu cliente. Para tanto, elegemos a abordagem qualitativa de pesquisa, com informações obtidas através de entrevista semiestruturada. Nosso estudo contou com sete participantes mulheres, com idade mínima de dezoito anos e envolvimento com a prática da prostituição há pelo menos um ano. As participantes responderam um questionário socioeconômico e foram entrevistadas, sendo as entrevistas posteriormente submetidas à análise de conteúdo. Com base nas informações obtidas, concluímos que a relação estabelecida entre prostitutas e seus clientes fundamenta-se no dinheiro, tanto em relação ao que o cliente paga quanto em relação àquilo que ele não pode pagar, porque "não tem preço". Essa negociação serve de alicerce para o estabelecimento de condições de ser-estar dessas mulheres profissionais do sexo dentro e fora da prostituição.
\end{abstract}

Palavras-chave: Prostituição; afeto; sexualidade.

\section{MONEY, AFFECTION AND SEXUALITY: THE PROSTITUTES' RELATIONSHIP WITH CLIENTS}

\begin{abstract}
Prostitution is constantly the aim of various different looks and academic research. With the objective of unveiling some of its meanings we have chosen to investigate the relationship - in its wider sense - between prostitutes and their clients. In order to do so, we elected the qualitative research method collecting information through semi-structured interviews. We investigated seven women of 18 years old minimum and involved in the activity for at least a year, who answered a social-economics questionnaire before being interviewed. The interviews were later submitted to the content analysis. Based on the results, we have concluded that the relationship between the prostitute and her client is founded on money - on what the client can pay for as well as on what cannot be paid for because is priceless. Such negotiation constitutes the basis for the establishment of their sense of being, in or out of the prostitution practices.
\end{abstract}

Key words: Prostitution; affection; sexuality.

\section{DINERO, AFECTO Y SEXUALIDAD: LA RELACIÓN DE PROSTITUTAS COM SUS CLIENTES}

\begin{abstract}
RESUMEN. La prostitución es objetivo constante de diferentes puntos de vista y a fin de aclarar algunos de sus significados, se optó por estudiar la relación establecida entre la prostituta y su cliente. Así, elegimos un enfoque cualitativo de la investigación, con la información obtenida a través de entrevista semiestructurada. Nuestro estudio contó con la presencia de siete participantes del sexo femenino, con edad mínima de 18 años y su participación en el ejercicio de la prostitución en al menos un año. Las participantes respondieron a un cuestionario socioeconómico y fueron entrevistadas, y las entrevistas posteriormente objeto de análisis de contenido. Podemos concluir que la relación establecida entre las prostitutas y sus clientes se basa en el dinero, tanto en relación a lo que el cliente paga, así como en lo que respecta a lo que él no puede pagar porque "no tiene un precio". Este acuerdo sirve como base para el establecimiento de las condiciones de el ser y bienestar de estos trabajadores del sexo femenino dentro y fuera de la prostitución.
\end{abstract}

Palabras-clave: Prostitución; afecto; sexualidad.

\footnotetext{
Mestranda em Psicologia pela Universidade de São Paulo e membro do Grupo de Pesquisa Sexualidade-Vida - USP/CNPq.

\# Doutorando em Psicologia pela Universidade de São Paulo, mestre em Psicologia pela Universidade de São Paulo. Especialista pela PUC-PR e pela UFPR. Professor da Faculdade Campo Real. Membro do Grupo de Pesquisa Sexualidade-Vida -USP/CNPq.

II Doutora em Psicologia Educacional pela UNICAMP. Especialista em Sexualidade Humana, Psicanalista, Pedagoga Docente/Pesquisadora/ credenciada no Programa de Pós-Graduação em Psicologia do Departamento de Psicologia da Faculdade de Filosofia Ciências e Letras da USP - Campus de Ribeirão Preto - SPLíder do Grupo de Pesquisa SexualidadeVida-USP/CNPq.
} 
O fenômeno da prostituição constitui-se em um campo amplo e complexo, objeto de inúmeros estudos, opiniões, interesses, preconceitos e nomenclaturas. É uma temática extremamente debatida, que suscita opiniões e teorias tanto do senso comum quanto da academia. Em vista de sua abrangência, é possível entender a razão de ser esta temática perpassada por tantos discursos e abordada de maneiras tão distintas. Entre as diferenças encontradas nas várias formas como a prostituição é entendida e tratada em nossa sociedade destacam-se a sua denominação e a de suas representantes, que vão desde termos de cunho pejorativo até nomes com muito "enfeite" e pompa. Cumpre aqui observar que no presente trabalho foram utilizados como sinônimos os termos profissional do sexo e prostituta. Conforme afirma Leite (2009), em se tratando da organização da movimentação política das prostitutas, "para o movimento é importante assumir o nome e não fugir dele" (p. 158). Dessa forma, esclarecemos que a utilização das duas denominações se deu apenas no sentido de não saturar o texto com apenas uma das nominações; no entanto, temos consciência de que essa discussão é muito mais complexa e extrapola o simples ato de nomear uma categoria.

É justamente pela complexidade desta temática que a prostituição é tão estudada e os mais variados discursos são gerados, na busca por compreendê-la tanto em relação à sua origem quanto às especificidades inerentes a essa prática sexual, entre elas as relações estabelecidas entre as prostitutas e seus clientes. Russo (2007) considera que a procura por profissionais do sexo é motivada pela busca de um tipo específico de mulher, de prazer ou de fantasia sexual, de forma que não se trata de um serviço prestado por qualquer sujeito do sexo feminino, mas por uma mulher especifica - a prostituta -, pois esta está inserida em um contexto particular, que proporciona sensações próprias e uma gama de possibilidades e experiências específicas. A autora salienta ainda que o homem (optamos por investigar este fenômeno na relação heterossexual) busca especificamente essa relação de sexo pago; afinal, o ato sexual "gratuito" pode ser conseguido de várias outras formas.

Pasini (2005) discute que, apesar de já existir uma categoria para as profissionais do sexo na Classificação Brasileira de Ocupações, essas mulheres permanecem marginalizadas, pois, embora nosso país não entenda a prática da prostituição em si como um crime, todo o mercado a ela relacionado é considerado crime. Este fato caracteriza o que Pereira (1976) descreveu como uma atitude abolicionista da prostituição, sendo tratada como prática imoral, mas não ilícita, eliminando, dessa forma, o controle estatal.
Assim, é facilmente constatável que, mesmo que não sendo uma atuação ilícita, a prostituição ainda é uma prática muito marginalizada e suas representantes continuam sendo consideradas depravadas pela sociedade em geral.

Para Russo (2007), tal marginalização se deve ao estigma presente na prostituição. Estigma é entendido por Goffman (1988) como pré-concepções que são transformadas em expectativas normativas, definindose como exigências sociais apresentadas de forma rigorosa. Assim, a estigmatização desconsidera quaisquer aspectos bons que determinada pessoa ou grupo possa ter e foca apenas os ruins, e dessa forma diminui a pessoa estigmatizada, reduzindo seu valor. Assim, uma das características essenciais do estigma é a intensidade do seu efeito de descrédito, sempre desproporcional e muito grande, pois trata-se de uma discrepância entre a identidade social virtual dessa pessoa e sua identidade social real.

Articulando o conceito goffmaniano de estigma com a prostituição, Russo (2007) entende que existe aí uma relação variável, no sentido de que o estigma não atinge todas as profissionais do sexo, sendo sua existência inversamente proporcional ao montante pago pelo programa: quanto menor é o valor pago maior é o estigma, e vice-versa. A autora pondera ainda que quanto maior é o valor pago, mais a mulher se afasta da estereotipia tão característica da prostituta, sendo modificada até mesmo a denominação utilizada para se referir a ela. Assim, é possível perceber o status que perpassa essa atuação e as diferentes formas de tratamento das profissionais do sexo de acordo com a classe social a que pertencem e a que atendem.

Com base nos argumentos já brevemente apresentados, é possível relacionar as profissionais do sexo da baixa prostituição à esteriotipia clássica dessa atuação, objeto de preconceitos e discriminações e de termos pejorativos como o de promiscuidade, como exemplifica Duarte (2006). Não obstante, a prostituição não pode ser enxergada como a última saída para essas mulheres ganharem dinheiro, visão que as torna vítimas; deve-se considerar a escolha por esse caminho como meio de obter dinheiro, o que certamente não tem relação direta com promiscuidade (Guimarães, 2007).

Além da questão crucial que é a razão de algumas mulheres recorrerem à prostituição, É preciso considerar também o outro lado, o dos clientes e os motivos que os levam a procurar as profissionais do sexo - afinal de contas, conforme nos esclarece Bruns (2001), "Se existe quem vende prazer, é porque existe quem compra prazer. Não há negócios estabelecidos unilateralmente. Não seria o poder de compra o desencadeador do desejo ou necessidade de venda?" ( p. 15). 
É nessa perspectiva que Farinha e Bruns (2006) contextualizam a escolha pela prostituição tanto da mulher como do cliente enquanto mecanismo do sistema capitalista, principalmente no tocante à relação entre compra e venda de produtos, incluindo especificamente o corpo feminino. Por outro lado, é imprescindível reconhecer que o aspecto financeiro constitui apenas um desdobramento dessa temática, que de forma alguma pode se encerrar unicamente na questão do dinheiro.

Essas autoras consideram ainda que há outros aspectos presentes na prostituição. Entendem elas que, além da relação sexual entre a profissional do sexo e o cliente, ocorre também uma relação intersubjetiva; afinal, ambos constroem um sentido para o relacionamento, que pode ser tanto de simpatia quanto de aversão. Este outro meandro da prostituição pode ser constatado também em Russo (2007), que se propôs a discutir especificamente a relação da profissional do sexo com o seu cliente pelo viés do dinheiro, mas percebeu que não há como restringir a prostituição à relação de troca econômica, pois esta troca é perpassada não só pelos valores econômicos, mas também pela afetividade, pelo encontro de duas pessoas e pelo rompimento da solidão corporal delas.

Assim, a prostituição deve ser entendida como uma forma de troca - tanto econômica quanto sexual que ultrapassa a si mesma, pois nesse universo são construídas identidades e relações sociais, ambas imersas em valores tanto econômicos quanto de ordem afetiva, como bem pontua Russo (2007). Postas todas essas questões, o objetivo deste trabalho é investigar quais os aspectos que interferem na relação diádica da profissional do sexo com seu cliente, considerando para tal as mais variadas minúcias que perpassam esta prática sexual, desde o motivo óbvio - o sexo pago até os aspectos representados por questões como a escolha da profissional do sexo pelo cliente, as práticas sexuais realizadas, os riscos da atuação e também a afetividade.

\section{METODOLOGIA}

O referencial metodológico adota a metodologia de pesquisa qualitativa, a qual reivindica uma forma de pesquisar mais dinâmica, embasada na construção constante de espaços de inteligibilidade que permitam a discussão e o aprofundamento do tema em questão, ao invés de tentar esgotá-lo com a realização de uma pesquisa isolada (Rey, 2005). De acordo com Serapioni (2000), essa metodologia é muito bem empregada em objetos de estudo que não são muito conhecidos, como é o presente caso. Como justifica o autor, esse posicionamento faz emergirem novos significados, além das relações, motivações e comportamentos diversos que não seriam observados de outra forma, como com a simples aplicação de um questionário, por exemplo. Com base nessas considerações, buscamos um conhecimento provisório, capaz de gerar espaços de inteligibilidade para que a discussão sobre o tema pesquisado - a relação da prostituta com seus clientes - não se esgote, pelo contrário, venha a se ampliar.

\section{Instrumentos de coleta de informações}

A maneira escolhida para ter acesso às informações da pesquisa foi uma entrevista semiestruturada, que, de acordo com Minayo (2007), é um instrumento privilegiado para as Ciências Sociais, pois considera a fala como reveladora de condições estruturais, normas, símbolos e sistemas de valores e é capaz de transmitir representações grupais importantes. A autora destaca que há representatividade na fala de uma pessoa em particular, pois tanto o comportamento individual quanto o social obedecem a alguns modelos culturais que são interiorizados por todos. Dessa forma, fica justificada a razão de esse modelo de pesquisa não requerer um número significativamente alto de participantes.

No intuito de realizar as entrevistas, no decorrer do ano de 2009 foram realizadas visitas aos locais de trabalho das prostitutas, tanto nos bares quanto nos "pontos" que elas estabelecem nas ruas. Apesar da facilidade em encontrá-las, houve dificuldade em conseguir envolvê-las na pesquisa, principalmente no tocante à gravação da entrevista. Assim, foi feito contato com um projeto municipal de atendimento a profissionais do sexo no qual a maior parte delas é cadastrada e onde são realizados exames médicos e distribuídas camisinhas, com vista a uma prática mais segura. Os profissionais do projeto permitiram a realização da pesquisa e a permanência dos pesquisadores na sede do projeto, o que facilitou o contato com as participantes e a realização de todas as entrevistas, que ocorreram na própria sede do projeto durante o mês de julho de 2009. Além disso, a pesquisa contou com o questionário de classificação econômica da Associação Brasileira de Estudos Populacionais (ABEP), a fim de poder classificar as informações referentes à classe social das participantes.

\section{Participantes}

Como participantes foram escolhidas sete profissionais do sexo de baixo e médio meretrício, atuantes nas ruas e também em bares e boates no Interior do Paraná, sendo que a escolha se deu por 
conveniência e também por indicação de um projeto público que atende às prostitutas. Como critério de participação foi definido a participante ter a idade mínima de dezoito anos e tempo mínimo de atuação na prostituição de um ano. Todas as participantes assinaram um Termo de Consentimento Livre e Esclarecido, que explicou os procedimentos da pesquisa, garantindo o respeito aos aspectos éticos.

Consideradas essas condições iniciais, as participantes compuseram o seguinte perfil: encontravam-se na faixa etária entre 22 e 61 anos; a maior parte delas pertencia à classe social $\mathrm{C}$, sendo uma classificada na classe E, e outra na B2; todas eram mães, eram solteiras e não tinham companheiro fixo à época da pesquisa. Todas atuavam na prostituição havia pelo menos quatro anos e cobravam entre 30 e 50 reais por programa. Essas mulheres relataram trabalhar quase todos os dias da semana, sendo que os locais de atuação variavam entre a rua, boates e bares.

\section{Análise das informações}

Finda essa etapa inicial de coleta das informações, com as entrevistas gravadas e transcritas na integra, foi realizada a análise dessas informações utilizandose o referencial da análise de conteúdo. De acordo com Campos (2007), essa perspectiva de análise busca o que há de oculto em entrevistas, falas e até mesmo observações por meio de inferências, procurando, assim, compreender a subjetividade dos indivíduos pesquisados. $\mathrm{O}$ autor pontua ainda que a utilização da inferência não significa a inexistência de rigor metodológico, pois são adotados critérios científicos para que haja confiabilidade no método.

Para Rey (2005), a análise de conteúdo apoia-se na categorização das informações obtidas em unidades parciais fragmentadoras do objeto estudado, as quais serão depois unidas novamente ao processo de interpretação da pesquisa. Considerando esse processo, estabelecemos duas categorias, cada uma delas constituída por diversas subcategorias relacionadas, conforme apresentaremos a seguir:

1. "O que o dinheiro paga"

Esta categoria expõe os aspectos mais objetivos da prostituição e da relação da profissional do sexo com os seus clientes, apresentados nas seguintes subcategorias:

- Entrada e permanência no mercado sexual;

- Motivações que atribuem à busca dos clientes pela prostituição;

- O julgamento que elas fazem dessa relação;

- Dinheiro dos clientes é o mesmo;

- O prazer no ato sexual com o cliente;
- Riscos envolvidos na prostituição.

2. "Não há dinheiro que pague".

Esta categoria aborda os aspectos mais subjetivos da prostituição e das barreiras existentes na relação estabelecida pela díade prostituta-cliente, conforme destacado nas subcategorias:

- Limites que as profissionais do sexo impõem para sua atuação;

- Nem tudo está à venda;

- Ressalva em relação à afetividade;

- Não há dinheiro que pague pela violência.

\section{RESULTADOS E DISCUSSÃO}

De acordo com Barros (2005), o dinheiro constitui-se como a principal ficha simbólica das relações de troca, pois consiste em um equivalente universal, impessoal e garantidor das relações de mercado. É precisamente esse seu aspecto multifacetado que a categoria "O que o dinheiro paga" se propõe a discutir, investigando as formas como este influencia a estrutura do mercado do sexo para as prostitutas. Tal é a sua relevância, principalmente em se tratando do baixo meretrício, que serve como justificativa e motivo alegado pelas prostitutas para sua entrada e permanência no mercado sexual.

Essa importância atribuída ao dinheiro pode ser constatada nas falas das participantes no que se refere ao seu ingresso na prostituição, nas quais todas justificaram ter iniciado essa prática pela necessidade financeira. Apesar de as razões de cada uma das entrevistadas serem específicas, próprias de cada contexto, a maior parte iniciou-se na prostituição para garantir seu sustento, naturalmente, estando sempre envolvidas as questões familiares. Essa informação corrobora o exposto por Gaspar (1985) quando destaca que as profissionais do sexo utilizam-se da justificativa econômica para ingressarem e permanecerem na prostituição de baixo meretrício, pois muitas vezes ocupam o papel de chefes de família e encontram nessa prática uma forma de sustentá-la.

Não obstante, o fato de conseguirem sustentar seus filhos e terem uma vida melhor com o exercício da prostituição não significa que elas gostem do que fazem - ao contrário, todas se mostraram insatisfeitas com a prática, apesar de demonstrarem certo sentimento de acomodação e conformismo quanto a ser esse o seu destino. Interessa ressaltar que uma das profissionais do sexo relatou sentir grande aversão à prostituição, inclusive afirmou que está parando com os programas, realizando-os somente em casos de 
extrema dificuldade financeira e apenas até conseguir receber legalmente a pensão de um dos filhos.

Focando o outro lado dessa díade, no que diz respeito às motivações que elas atribuem à busca dos clientes pela prostituição, três das entrevistadas afirmaram que os homens procuram nas prostitutas o que não encontram em suas esposas, seja no tocante à realização de desejos sexuais seja pela atenção e conversa, como exemplificado na seguinte fala " $E$ eles saem procurá um carinho, uma atenção, uma companhia, porque eles não tem na casa" (Entrevistada 4, 2009). As respostas das entrevistadas vão ao encontro das proposições destacadas por Pizani (1994), as quais colocam a relação estabelecida entre a prostituta e os clientes como marcada por uma dinâmica sexual que eles não estabelecem com suas mulheres, sendo possível inclusive manter relações com uma profissional do sexo mais atraente e instigante.

Não obstante, conforme já apontado por outros pesquisadores, essas motivações não são exclusivamente sexuais. As profissionais do sexo de nosso estudo corroboraram que os clientes não as procuram exclusivamente para práticas sexuais, muitas vezes desejam apenas conversar e desabafar as preocupações e problemas relacionados à família, ao trabalho e à própria masculinidade (Silva, 2006), como pode ser observado no relato de uma das entrevistadas:

"Então, às vezes, em vez de você ser uma
garota de programa você acaba sendo uma
psicóloga também, entre aspas, né? Porque
começa a dá dica e naquela hora você não
age como uma garota de programa, você age
como uma mulher, pro cara entender que
aquela mulher que tá em casa, que é esposa
dele, nâo tá sendo bem tratada"
(Entrevistada 5, 2009).

Nas falas das participantes foi possível perceber a imensa gama de motivações que levam os clientes a buscar as profissionais do sexo. Tanto por parte delas quanto deles, percebe-se que ambos se utilizam do dinheiro para suprir suas necessidades - eles pagando e elas recebendo. Assim, nessa díade, ambos estão à procura de suprir suas carências, sejam elas econômicas, emocionais, psicológicas ou ainda biológicas. Para o homem, o dinheiro paga, além da satisfação de determinadas carências, pela manutenção de uma sexualidade masculina herdada do modelo patriarcal de ser homem.

Entendendo o viés comercial do acordo estabelecido entre as profissionais do sexo e seus clientes, interessamo-nos em conhecer o julgamento que elas fazem dessa relação. Buscamos, para tanto, entender de que maneira as profissionais do sexo avaliam essa relação de troca. Diante dessa questão, encontramos discursos variados e opostos. A maior parte delas relatou que a relação estabelecida com o cliente é boa, amigável, enquanto outras afirmaram tratar-se de uma relação difícil, pois os clientes querem impor suas vontades. Uma delas apontou o aspecto da diversidade: disse que esse relacionamento é variável, oscilando de acordo com cada cliente.

Além da divergência presente nos julgamentos, percebe-se que essas mulheres caracterizam a relação estabelecida com o cliente de acordo com as atitudes dele. Assim, quando ele as trata bem, a relação é considerada boa, mas se as trata mal, esse julgamento é prejudicado e a relação é considerada ruim. Entendemos daí que as prostitutas acabam responsabilizando os seus clientes pela relação estabelecida entre ambos, deixando subentendido que não cabe a elas nenhuma ação para estabelecer um bom relacionamento. Apesar da incerteza quanto à satisfação da relação, que oscila entre esses dois polos, a motivação para que ela aconteça é uma constante: o dinheiro, o que pode ser exemplificado pelas seguintes falas "É que na verdade, na maioria das vezes, quando a pessoa faz programa, não é por prazer, é mais por dinheiro, sabe?" (Entrevistada 2, 2009); "Eu não gosto, eu só vou porque eu preciso mesmo, né?" (Entrevistada 6, 2009); e ainda pela seguinte fala:

\footnotetext{
"Geralmente aqui são todas mães e pais de família, né? Então, são mães de dia e pais à noite, então é difícil guardar, né? Esses clientes são os que salvam a gente, né? Querem a diversão e a gente qué a grana, né? Só também" (Entrevistada 5, 2009)
}

Essa motivação monetária foi percebida no discurso de todas as sete entrevistadas, as quais acentuaram que o programa é baseado unicamente no dinheiro. Assim, elas não estão em busca de um tipo especifico de relação, mas do dinheiro pago por ela, reafirmando uma vez mais o caráter profissional da atuação.

Gaspar (1985) nos ensina ainda que, apesar de parecerem desagradáveis, os sentimentos hostis das prostitutas em relação a determinados clientes são justificados por elas como o caráter profissional da prostituição, pois, como não se sentem atraídas pelos clientes, fazem o programa única e exclusivamente pelo dinheiro.

A importância atribuída ao dinheiro se reflete também na questão do atendimento aos clientes, que, de acordo com a maior parte das entrevistadas, tem de ser "geral", no sentido de não haver critério de escolha quanto à aparência física dos clientes. Quando questionadas sobre a escolha dos clientes, três 
entrevistadas afirmaram que não há muitos critérios "A necessidade escolhe, querida", afirma uma delas, “... eu acho que o dinheiro das pessoas tem o mesmo valor. Você me entende? Tanto faz, seja rico, seja pobre, seja sujo, seja limpo, velho ou novo, tem o mesmo valor". Assim, essas prostitutas entrevistadas relatam desconsiderar a aparência física dos clientes, interessando-lhes apenas o dinheiro. Destacam que o dinheiro dos clientes é o mesmo, demonstrando, com isso, mais uma vez, o distanciamento emocional e o caráter profissional da prática.

Esta "profissionalização" da prática da prostituição - se assim pode ser chamada - presente nos discursos das prostitutas corrobora os estudos de Russo (2007), que argumenta que diante do dinheiro, a dimensão pessoal é embotada e a relação é cada vez mais impessoal, eliminando a ideia de pagamento baseado nos atributos pessoais de cada um. Dessa forma, pontua a autora que nesse tipo de relação o desejo, o prazer e a sedução estão relacionados à negociação econômica, e não a atributos físicos específicos.

A maioria das falas demarca claramente a atuação profissional na prostituição, visando primeira e primordialmente ao dinheiro. Apesar disso, pode haver questões para além do dinheiro, como, por exemplo, o prazer no ato sexual com o cliente. Três das entrevistadas afirmaram ser possível satisfazerem-se sexualmente nas relações com os clientes. Por razões distintas, cada uma conta como acontece. Enquanto para uma o prazer pode ser obtido de acordo com o carinho recebido, para outra, é muito difícil acontecer assim; mas ela afirma que quando ocorre é bom, porque está recebendo o dinheiro necessário e ainda obtendo prazer; e para a terceira, o prazer depende da sua abstinência sexual.

$\mathrm{Na}$ verdade, apenas a minoria das entrevistadas afirmou sentir prazer no ato sexual com os clientes, o que corrobora a literatura acerca dessa temática. Gaspar (1985) pontua que muitas das profissionais do sexo evitam o orgasmo para marcar o caráter exclusivamente profissional da relação e Barros (2005) vê o orgasmo da prostituta como um acidente de trabalho, que raramente acontece, pois, para o autor, elas estão preocupadas em controlar o tempo, a posição e os carinhos que possam adiantar o gozo do cliente.

Pasini (2000) entende a questão dos limites e, mais especificamente, do orgasmo da profissional do sexo de forma mais flexível, pontuando que esses não são tão fixos quanto aparentam, possibilitando abertura de algumas ressalvas, dependendo, para tanto, de como a prostituta está se sentindo naquele dia ou ainda do tipo de cliente atendido. A autora se utiliza dessas justificativas ainda para explicar o orgasmo da profissional do sexo com o cliente, ressaltando que quando ocorre na relação é percebido por elas como uma sensação física, sem afeto algum.

Se, por um lado, eventualmente, o dinheiro acaba pagando também pelo prazer das prostitutas, por outro esse mesmo dinheiro paga pelos riscos envolvidos na prostituição. Mesmo tomando certas precauções, os riscos inerentes à prática são conhecidos. Esse aspecto foi percebido de várias maneiras pelas entrevistadas, sendo o perigo de contrair doenças sexualmente transmissíveis citado pela maior parte. Pontuaram que, mesmo com a utilização do preservativo masculino, que todas afirmaram ser um critério de escolha do cliente, o perigo está presente.

De fato, apesar de as prostitutas escolherem os seus clientes e imporem os critérios, os limites para a o programa, elas jamais estarão totalmente protegidas, pois, como afirma Pasini (2000), elas nunca sabem ao certo o que encontrarão no programa, entretanto, esse risco não interfere na atuação dessas mulheres, que continuam realizando seus programas - o que nos leva a pensar que o dinheiro ganho com a prostituição paga também pelos riscos.

Considerando todos esses aspectos da prostituição, concordamos com Farinha e Bruns (2006) quando afirmam que a relação entre a profissional do sexo e o cliente é marcada pela impessoalidade, pelo faz-de-conta - ela vende ao seu freguês a ilusão de dominação e responsabiliza-se pela satisfação dele, assim, o que está à venda é de caráter profissional, no sentido da prestação de um serviço. Neste contexto, consideramos que o dinheiro constrói uma relação que envolve dois corpos e dois desejos distintos, caracterizando-se como uma relação profunda, mesmo que efêmera - marcada pela impessoalidade, mas não pela indiferença, pois, como afirmam os autores, o fato de a profissional do sexo proporcionar prazer aos seus fregueses não significa que ela, necessariamente, goste de todos eles e faça tudo para satisfazê-los. Esta atitude nos sugere que nem tudo está à venda. Feita esta colocação, passemos para a categoria seguinte.

A categoria "Não há dinheiro que pague" abarca questões presentes no universo da prostituição que não são negociáveis, ou seja, não há dinheiro que tudo pague. Entre essas questões se destacam, inicialmente, alguns limites que as profissionais do sexo levantam para sua atuação, entendidas por nós como recursos defensivos, seja contra a violência, para diminuir os riscos, seja para preservar sua subjetividade diante dessa prática sexual. Nesse intuito de proteção de si mesmas, as profissionais do sexo acabam por estabelecer condições para que o programa aconteça. Cinco das entrevistadas citaram duas condições das quais não abrem mão: o uso do preservativo masculino 
nas relações sexuais e a não realização de sexo anal, condições que são combinadas previamente com os clientes, de forma a não haver problemas posteriormente.

Essas regras estabelecidas pelas entrevistadas corroboram aquelas descritas por Pasini (1999) quando afirma a necessidade das prostitutas de organizar a relação com o cliente. A autora ressalta, ainda, o uso do preservativo masculino como a condição mais respeitada, sendo respaldada pelas ações de higiene, de demarcação de sentimentos e de separação entre a vida pessoal e a profissional. Essa autora salienta o valor do preservativo, que, além de proteger contra doenças sexualmente transmissíveis, protege a subjetividade das mulheres, pois se constitui como um divisor simbólico entre as diferentes relações sociais, sejam estas afetivas ou comerciais. Também Gaspar (1985) pontua essa demarcação como imprescindível para separar o lado emocional do profissional, pois o que não é feito com os clientes pode ser guardado para os companheiros, afinal, de acordo com a autora, 'Uma mulher pode fazer 'tudo', inclusive uma série de práticas condenáveis até mesmo para muitas prostitutas desse meio, mas ela sempre criará um limite simbólico que demarque relações e envolvimentos profissionais" (p. 118).

Essas justificativas de demarcação entre o profissional e o afetivo não foram encontradas explicitamente em nossa pesquisa, pois nenhuma das participantes mantinha um relacionamento afetivo fora da prostituição; porém há outras restrições, mais específicas, próprias de cada entrevistada, que demonstram demarcações carregadas de valor simbólico. Por exemplo, uma delas não sai com homens mais novos, outra não permite agressão física, além de não fazer programa com clientes sujos e bêbados; uma terceira participante só faz programa com homens que tenham uma situação financeira melhor que a dela, não aceitando sadomasoquismo, apesar de realizar atos masoquistas com o freguês, caso ele o queira, e também não beija os seus clientes na boca; e uma quarta participante relatou que não sai com clientes que a maltratam, seja física seja moralmente.

Considerando as entrevistas, percebemos que todas as participantes apresentam particularidades em relação ao atendimento a clientes, conforme suas próprias subjetividades. Essas questões específicas de cada prostituta já foram abordadas por autores como Gaspar (1985), Martin (2003), Silva (2006) e Pasini (2000), em discussões acerca do corpo e suas bordas como legitimadores das relações e parcerias estabelecidas tanto dentro quanto fora da prostituição, corpo este que ultrapassa a função meramente sexual para elaborar significados sociais de ser-estar no mundo público e privado.

Independentemente de quais sejam as restrições estabelecidas por cada prostituta, Pasini (1999) sugere ser imprescindível o respeito às normas por ela impostas, pois essas são inscritas em seus corpos de tal forma que dão visibilidade à sua atuação na prostituição, assim como são responsáveis pelas relações sociais. Desse modo, entendemos que todas as condições explicitadas por nossas entrevistadas levam a um mesmo fim: nem tudo está à venda, mesmo em se tratando de prostituição.

Para Sousa (1998), há uma representação errônea da profissional do sexo: as pessoas, de modo geral, supõem que a prostituta faz tudo o que o cliente desejar; entretanto, como afirma a autora, a maior parte delas faz o mesmo que qualquer mulher pode fazer - o sexo trivial. Assim percebemos que, embora as profissionais do sexo sejam pagas pelo cliente para satisfazê-los, são elas quem dão a palavra final do programa. Pasini (2005) discute essa questão específica do agenciamento do programa, pontuando o empoderamento das prostitutas. A autora percebe que seus corpos e sua prática não são tão alienados e vitimizados quanto parecem ser, pois, "apesar de estarem na rua e, a princípio dispostas a realizarem sexo em troca de dinheiro, mostram que também são mulheres dotadas de vontades e escolhas" (p. 5).

$\mathrm{Na}$ esteira de Pasini (2005), Corona (2007) afirma que não é por trabalharem com sexo que as prostitutas terão valores liberais em relação às práticas sexuais, ou até mesmo à sua vida afetiva. Gaspar (1985) já esclarecera que, apesar da possibilidade de lucrar mais tomando certas atitudes na relação sexual, ou ainda de obter prazer com o seu cliente, pode existir um limite estabelecido pelas profissionais do sexo. Este não é somente referente a aceitar ou não um cliente, mas também a aceitar ou não determinadas práticas sexuais, denotando uma necessidade de reserva, como constatado nas falas das prostitutas por nós entrevistadas.

Além dessas condições relacionadas à atuação sexual, encontramos outra restrição demarcadora da prática das profissionais do sexo: a ressalva em relação à afetividade. $\mathrm{A}$ maior parte de nossas entrevistadas - seis participantes - afirmou não poder existir esse tipo de envolvimento com os clientes; mas uma delas defende que esse envolvimento pode acontecer, dependendo da afinidade existente na díade, e afirma já ter se envolvido com muitos de seus clientes. Assim a maior parte das entrevistadas garante que o envolvimento não deve passar do nível profissional, caso contrário o cliente deixa de sê-lo e torna-se parte da vida delas. 
As entrevistadas que afirmaram não ter com os clientes envolvimento além do sexual, fizeram-no acentuando já ter acontecido isto no passado, e muitas delas inclusive tiveram filhos com esses clientes com quem se envolveram afetivamente. Isto nos leva a hipotetizar que justamente por causa dessas consequências é que constituíram o não envolvimento afetivo como restrição na relação com o cliente, de forma essencialmente subjetiva.

Segundo Pasini (2000), a delimitação da prática sexual com o cliente pode ser percebida como fruto de um corpo mercadoria, diferentemente do corpo afeto, característico das relações pessoais. Seguindo essa mesma lógica, Pinho (2006) afirma que as prostitutas vivem uma sexualidade inscrita no lucro, assim o envolvimento afetivo compromete a lucratividade, e é exatamente esse envolvimento que as participantes da nossa pesquisa procuram evitar.

Assim como há uma ressalva quanto à afetividade no relacionamento com o cliente, há ainda outra restrição que merece ser ressaltada: a violência (que muitas vezes é demandada pelos clientes), seja física ou psíquica. Para as profissionais do sexo, não há dinheiro que pague pela violência, a não ser, como pontua Russo (2007), quando consentida e acordada previamente. Apesar disto, muitos clientes sentem-se no direito de violentar as prostitutas, pelo fato de estarem pagando pelo programa e assim terem direito a demandar que elas façam tudo o que eles desejarem, aguentando todo tipo de ofensa. Em relação à violência física, quatro de nossas entrevistadas nunca foram agredidas, enquanto as outras três já vivenciaram situação de agressão na prática da prostituição.

Russo (2007) salienta que a desvalorização total da profissional do sexo é sentida em casos de violência, que incluem desde agressão física até violência simbólica, sendo entendidos pela autora como o não pagamento do programa, a imposição do medo e várias formas de humilhação. Quatro de nossas entrevistadas já foram vítimas deste último tipo de agressão, o qual Barros (2005) considera mais grave do que a violência física, pois é manifestada no olhar, nas duras falas e comportamentos. O autor discute ainda que essa forma de violência é sentida quando as profissionais do sexo são comparadas a outras mulheres ou ainda a animais, sendo constantemente inferiorizadas.

Assim, uma vez mais, o dinheiro aparece como estruturante da relação entre a profissional do sexo e o cliente, dinheiro que, para elas, não paga agressões, mas, para eles, as justificam. Martin (2003) pontua que as prostitutas, ao acordarem o programa com um cliente, já o fazem sabendo da possibilidade de que algo pode dar errado, pois, nas palavras da autora, "O cliente é, na maioria das vezes, um desconhecido cujo comportamento pode surpreender quando se vê a sós com ela" (p. 188); porém este é reconhecidamente um risco inerente à prática da prostituição.

\section{CONSIDERAÇÕES FINAIS}

Tendo em vista as variadas concepções teóricas acerca da prostituição e o relato de suas práticas, aos quais tivemos acesso por meio das entrevistas com sete profissionais do sexo, pudemos construir alguns significados acerca da relação das prostitutas com seus clientes, assim como foi possível também desconstruir outros. Para tanto, focamos nossa análise nos diversos aspectos da prostituição que emergiram da fala das participantes, mantendo sempre, presente como pano de fundo, a questão específica de sua relação com o cliente, que certamente permeia todo o discurso acerca do mercado sexual. Ainda outra questão que norteou nossa análise foi o dinheiro e o seu valor inerente nem sempre monetário -, no sentido de que, apesar de a prostituição caracterizar-se como uma relação de troca, como prestação de serviços, nem tudo pode ser trocado ou vendido. Dessa forma, relacionamos nossa discussão a respeito da relação estabelecida entre a profissional do sexo e o cliente com a questão específica do dinheiro e de seu alcance de compratroca.

Percebemos que a prostituição envolve relações entre a prostituta e o cliente em dois planos: o comercial e o intersubjetivo. No primeiro plano as relações são estritamente comerciais - relativas ao dinheiro pago pelo programa, e no segundo, de caráter intersubjetivo, incluem posicionamentos simbólicos, os quais não estão à venda. Esses dois planos demonstram que o dinheiro, por si, não garante o programa, podendo ser entendido como estruturante apenas das relações externas, comerciais, enquanto que os limites corporais podem ser vistos como estruturantes das relações internas, subjetivas. Dessa forma, podemos pensar que a relação da profissional do sexo com os seus clientes é apenas inicialmente comercial, pois o dinheiro é inerente à prática; no entanto, nem tudo pode ser pago. Assim, existem limites sexuais e afetivos que são intransponíveis, e é justamente por assim se caracterizarem que salvaguardam a saúde mental das profissionais do sexo e lhes permitem encarar esse trabalho como outro qualquer.

Estas reflexões e testemunhos nos levam a concluir que a prostituição abrange muito mais aspectos do que apenas o dinheiro, pois se constitui da relação de corpos, afetos e sexualidades próprias - tanto das profissionais do sexo quanto de seus clientes - de forma que cada um 
está vivenciando a relação de uma maneira: para aliviar as angústias do corpo ou as da alma.

A partir dessas investigações, podemos compreender um pouco mais acerca da relação estabelecida entre a profissional do sexo e seu cliente e perceber que, embora, em princípio, seja apenas comercial, ela, ainda que de forma mascarada ou proibida, abrange diferentes aspectos, como ilustrado ao longo deste texto.

\section{REFERÊNCIAS}

Barros, L. A. (2005). Mariposas que trabalham. Uma etnografia da prostituição feminina na região central de Belo Horizonte. Jus Navigandi, 8. Recuperado em 25 de outubro de 2009, de http://www.buscalegis.ufsc.br/revistas/files/journals/2/articl es/23535/public/23535-23537-1-PB.pdf

Bruns, M. A. T. (2001). A prostituição e sua nova embalagem. Conversando sobre sexualidade. São Paulo: Ômega.

Campos, D. C. (2007). Análise de conteúdo na pesquisa qualitativa. In M. N. Baptista, \& D. C. Campos. Metodologias de pesquisa em ciências: Análises quantitativa e qualitativa (pp. 265-288). Rio de Janeiro: LTC.

Corona, J. P. (2007). As meninas do centro: Família, sociabilidades e subjetivação entre mulheres prostituídas de rua em Florianópolis. Trabalho de Conclusão de Curso de Graduação em Ciências Sociais, Centro Filosofia e Ciências Humanas, Universidade Federal de Santa Catarina, Florianópolis. Recuperado em 5 de fevereiro, 2006, http://www.nigs.ufsc.br/site/tcc/joana_pagliosa.pdf

Duarte, B. N. (2006). Conhecendo a prostituta e o turista em um quarto de hotel: A representação social da prostituição na hotelaria de Juiz de Fora-MG. Trabalho apresentado ao GT "Turismo, Antropologia e Inovação" do IV Seminário de Pesquisa em Turismo do MERCOSUL - Caxias do Sul. Juiz de Fora: Universidade Federal de Juiz de Fora. Recuperado em 25 de outubro, 2009, de http://perseu.ucs.br:8080/ucs/tplPadrao/tplVSeminTur\%20/ posgraduacao/strictosensu/turismo/seminarios/semin_tur/pa gina/trabalhos/arquivos/gt10-06.pdf

Farinha, M. G., \& Bruns, M. A. (2006). Adolescentes profissionais do sexo. Campinas SP: Átomo.

Gaspar, M. D. (1985). Garotas de programa: Prostituição $e$ identidade social. Rio de Janeiro: Jorge Zahar Editor.

Goffman, E. (1988). Estigma: Notas sobre a manipulação da identidade deteriorada. Rio de Janeiro: LTC.

Guimarães, R. M. (2007). Prostituição: Patologia, trabalho, prazer? O discurso de mulheres prostitutas. Dissertação de Mestrado, Departamento de Psicologia da Educação, Faculdade de Filosofia, Ciências e Letras de Ribeirão Preto / USP, Ribeirão Preto.
Leite, G. (2009). Filha, mãe, avó e puta. Rio de Janeiro: Objetiva.

Martin, D. (2003). Riscos na prostituição: um olhar antropológico. São Paulo: Fapesp.

Minayo, M. C. S. (2007). O desafio do conhecimento: pesquisa qualitativa em saúde. São Paulo: Hucitec.

Pasini, E. (1999). Limites simbólicos corporais na prostituição feminina. Cad. Pagu, 14, 182-200. Recuperado em 25 de outubro, 2009, de http://www.ieg.ufsc.br/admin/downloads/artigos//Pagu/200 0(14)/Pasini.pdf

Pasini, E. (2000). Corpos em evidência, pontos em rua, mundos em pontos: A prostituição na região da Rua Augusta em São Paulo. Tese de Mestrado, Instituto de Filosofia e Ciências Humanas, Universidade Estadual de Campinas, Campinas, SP.

Pasini, E. (2005). Sexo para quase todos: a prostituição feminina na Vila Mimosa. Cad. Pagu, 25, 185-216. Recuperado em 27 de junho, 2008 de http://www.scielo.br/scielo.php?script=sci_arttext\&pid=S0 104-83332005000200008\&lng=pt\&nrm=iso >

Pereira, A. (1976). Prostituição: Uma visão global. Rio de Janeiro: Pallas.

Pinho, E. B. M. (2006). No amor e na batalha - memórias afetivas de mulheres prostitutas. OPSIS - Revista do NIESC, 6, 108-119. Recuperado em 24 de novembro, 2009, de

http://www.catalao.ufg.br/historia/revistaopsis/arqpdf/OPSI S2006.pdf\#page $=108$

Pizani, M. (1994). Formas de Prazer. Rio de Janeiro: Record.

Rey, F. L. G. (2005). Pesquisa qualitativa em psicologia: Caminhos e desafios. São Paulo: Pioneira Thomson Learning.

Russo, G. (2007). No labirinto da prostituição: o dinheiro e seus aspectos simbólicos. Cad. CRH, 20, 497-514. Recuperado de 20 de abril, 2009, de http://www.scielo.br/scielo.php?script=sci_arttext\&pid $=$ S0103-49792007000300009\&lng $=$ en $\& n r m=$ iso

Serapioni, M. (2000). Métodos qualitativos e quantitativos na pesquisa social em saúde: algumas estratégias para a integração. Ciênc. saúde coletiva, 5, 187-192. Recuperado em 2 de junho, 2009, de http://www.scielosp.org/scielo.php?script=sci_arttext\& pid $=$ S1413-81232000000100016\&lng=pt\&nrm $=$ iso

Silva, R. A. (2006). Prostituição: artes e manhas do ofício. Goiânia: Cânone Editorial.

Sousa, I. (1998). O cliente: o outro lado da prostituição. São Paulo: Annablume.

Recebido em 13-11-2011 Aceito em 08-05-2012

Endereço para correspondência: Fernanda Burbulhan. Praça Franklin Delano Roosevelt, 146, Consolação, CEP 01303-020, São Paulo-SP, Brasil.E-mail: fernanda_burbulhan@yahoo.com.br. 